\title{
Differences in the expression profiles of claudin proteins in human gastric carcinoma compared with non-neoplastic mucosa
}

\author{
LUOLUO YANG $^{1}$, XUN SUN ${ }^{2}$ and XIANGWEI MENG ${ }^{1}$ \\ Departments of ${ }^{1}$ Gastroenterology and ${ }^{2}$ Pathology, First Hospital of Jilin University, Changchun, Jilin 130021, P.R. China
}

Received August 26, 2017; Accepted March 1, 2018

DOI: $10.3892 / \mathrm{mmr} .2018 .9122$

\begin{abstract}
Numerous genetic alterations associated with cancer progression have the potential to serve as biomarkers for the early diagnosis of cancer. Numerous studies have suggested that claudin proteins, which are the primary components of tight junction structures, are associated with the regulation of cell polarity and cell differentiation. To investigate the expression profiles of the tight junction proteins claudin-2, -5 , -7 and -8 in gastric carcinoma, immunohistochemical analysis, western blotting and reverse transcription-quantitative polymerase chain reaction analysis was used to detect the expression profiles of these claudin proteins in gastric carcinoma tissues and in homologous non-neoplastic mucosal tissues. According to the present study, the expression levels of claudin-7 and claudin- 8 were downregulated, while the expression of claudin-5 was upregulated in gastric carcinoma tissues compared with in non-neoplastic mucosal tissues. Additionally, no notable difference was observed between claudin-2 expression in gastric carcinoma tissues and non-neoplastic mucosae. Correlations between claudin-7 and -8 expression and lymphatic metastasis in gastric carcinoma tissues were additionally reported. In summary, the present study revealed the distinct expression profiles of claudin-5, -7 and -8 in non-neoplastic mucosal tissues and gastric carcinoma tissues. Furthermore, the expression of these claudin proteins was highly associated with metastatic progression and prognosis in patients with gastric carcinoma, and had predictive value for the metastasis and survival of patients with gastric carcinoma.
\end{abstract}

\section{Introduction}

Epithelial cell sheets, which overlap over the external and internal surfaces of organs, function as a diffusion barrier

Correspondence to: $\mathrm{Dr}$ Xiangwei Meng, Department of Gastroenterology, First Hospital of Jilin University, 71 Xinmin Street, Changchun, Jilin 130021, P.R. China

E-mail: xwmjldx@126.com

Key words: tight junction, claudin-2, claudin-5, claudin-7, claudin-8, gastric carcinoma that regulates the selective permeation of substances and ions (1-3). It has been revealed that tight junctions (TJs) serve crucial functions in the formation of these cell sheets (4). TJs, which are composed of a network of strands that encircle the cells, form the closest contacts along the apical border of the cell membrane between epithelial cells $(5,6)$. At present, it is well accepted that TJs serve a crucial role in epithelial and endothelial physiology $(7,8)$. Considering that the majority of cancer is derived from the epithelium (9), the cellular processes that mediate the acquisition of a tumorigenic phenotype of epithelial cells have become an important area of scientific research $(10,11)$. Recently, the destruction of the structure of TJs has become a well-accepted factor that endows transformed epithelial cells with metastatic capability (12). Recent research has reported that TJs have a vital effect on cell polarity, and may additionally affect cell proliferation, metastasis and invasion. The destruction of the structure of TJs was revealed to lead to the disruption of epithelial cell cohesion and the promotion of epithelial cell invasiveness $(5,6,13)$.

The claudin proteins, which are the primary molecules involved in TJs, include 27 integral membrane proteins $(8,14,15)$. Claudin family members possess four transmembrane domains that form two extracellular loops, and amino and carboxyl terminal tails that extend into the cytoplasm (16). The extracellular loops of claudin proteins were revealed to be necessary for epithelial barrier integrity and for the maintenance of TJ structure and function $(17,18)$. Additionally, the claudin proteins were reported to interact with other TJ proteins and to be involved in cell signaling pathways via a PDZ domain in the C-terminus within the cytoplasm (14,19-23). These studies have suggested that the abnormal expression of claudin proteins may serve a particular role in cancer progression (24).

In the majority of tissues, the combination of numerous claudin proteins leads to the formation of TJS via homotypic or heterotypic interactions, or interactions with other TJ proteins $(25,26)$. Previously, it was suggested that the expression profiles of claudin proteins may vary among different tissue type (27). The functions of claudin proteins may be highly tissue-specific and may depend on the active molecular pathway in epithelial cells (28). Alterations in claudin expression are common phenomena that are associated with tumorigenesis and cancer progression (29). Thus, the objective of the present study was to investigate the expression profiles 
of claudins, which are TJ molecules, in gastric carcinoma and non-neoplastic mucosal tissues.

\section{Patients and methods}

Patients. Sections were collected from 100 patients with gastric carcinoma who were treated at the First Hospital of Jilin University (Changchun, China) during the period between October 2006 and September 2011. There were 61 males and 39 females and the patients' age ranged from 41 to 86 years with a median of 63 years. The cases were selected based on the following criteria: Pathologically confirmed diagnosis of gastric carcinoma; no previous malignant disease or second primary tumor; and no history of radiotherapy and chemotherapy. All the patients with gastric carcinoma were graded and classified according to the International Union against Cancer staging system (30). Histologically normal gastric tissues were additionally obtained from patients who were treated at the First Hospital of Jilin University during the period between October 2006 and September 2011 with inflamed or enlarged tonsils that were identified to be histologically non-neoplastic. There were 52 men and 48 women with average age of 43 years. The medical records of the patients were reviewed to determine the clinical and pathological characteristics. The follow-up durations were between 19 and 60 months. Among the patients, 46 were diagnosed with metastatic disease, 29 had recurrent tumors and 24 succumbed to mortality due to the disease. Prior patient consent was obtained from patients. The present study was approved by the Ethics Committee of Jilin University (no. 20100136) for the use of patient samples for research purposes.

Materials. Rabbit polyclonal antibodies against claudin-2 (cat. no. ab53032), claudin-5 (cat. no. ab15106), claudin-7 (cat. no. ab183738), claudin-8 (cat.no. ab192398), zonula occludens-1 (cat. no. ab96587), E-cadherin (cat. no. ab15148), GAPDH (cat. no. ab9485) were purchased from Abcam (Cambridge, MA, USA), and a UltraSensitive ${ }^{\mathrm{TM}}$ streptavidin-peroxidase immunohistochemistry reagent kit (cat. no. KIT-9710) was purchased from Fuzhou Maixin Biological Technology Development Company (Fujian, China).

Immunohistochemistry. An immunohistochemical analysis was performed according to the manufacturer's protocol of UltraSensitiveTM SP (Mouse/Rabbit) IHC kit (cat. no. KIT-9710, Maixin Biological Technology Development Company, Fujian, China). Sections (1.5 mm thick) were incubated at $4^{\circ} \mathrm{C}$ overnight with the rabbit anti-human claudin-2 antibody, the rabbit anti-human claudin-5 antibody, the rabbit anti-human claudin-7 antibody, the rabbit anti-human claudin- 8 antibody, the rabbit anti-human zonula occludens-1 antibody, the rabbit anti-human E-cadherin antibody diluted 1:450, 1:300, 1:350, 1:400 1:400 and 1:400 respectively. Subsequently, the slides were incubated with goat anti-rabbit amplification reagent (included in the IHC kit) for $30 \mathrm{~min}$ at room temperature and followed by incubation with diaminobenzidine (DAB) for $5 \mathrm{~min}$ at room temperature. For negative controls, the tissue sections were incubated with isotype antibodies (diluted at same concentration with primary antibodies) the at $4^{\circ} \mathrm{C}$ overnight. All sections were scored by two pathologists using a light microscope (E100; Nikon Instruments Inc, Japan; magnification, $\mathrm{x} 400)$.

Western blot analysis. Western blotting was used to detect the expression of claudin proteins in 12 human gastric carcinoma tissues and non-neoplastic mucosae, which were randomly selected from the 70 samples of gastric carcinoma tissues and homologous non-neoplastic mucosal tissues. Tissue lysates were prepared from each gastric carcinoma tissues and non-neoplastic mucosae, and protein concentration was determined using BCA Protein Assay Kit (Pierce; Thermo Fisher Scientific, Inc., Waltham, MA, USA). Western blotting was performed as previously described (31). Twenty micrograms of total proteins were separated on $10 \%$ SDS-PAGE and then transferred onto nitrocellulose membrane (Thermo Fisher Scientific, Inc.). Briefly, the membranes were probed overnight at $4^{\circ} \mathrm{C}$ with the aforementioned primary antibodies (anti-claudin-2, 1: 1,000; anti-claudin-5, 1:1,000; anti-claudin-7, 1:1,000; anti-claudin-8, 1:1,000 and GAPDH 1:1,000), and incubated with HRP-conjugated secondary antibodies (1:1,000 dilution; cat. no. 4414; Cell Signaling Technology, Inc., Danvers, MA, USA). Immunoreactive bands were detected using ECL western blot reagents (GE Healthcare, Chicago, IL, USA) and analyzed with Image Lab 6.0.1 Software (Bio-Rad Laboratories, Inc. Hercules, CA, USA).

Reverse transcription-quantitative polymerase chain reaction ( $R T-q P C R)$ for the detection of claudin $m R N A$. RNA was isolated from frozen specimens using TRIzol reagent (Thermo Fisher Scientific, Inc., Waltham, MA, USA) according to the manufacturer's protocol. RT-qPCR reactions were performed as previously described (32). The relative expression was based on the expression ratio of a target gene compared with that of GAPDH. The primers used were as follows: Claudin-2 forward, 5'-CCAACCTCAGCCAGAGAG AGG-3' and reverse, 5'-TCCCCAAACCCACTAATCACA-3'; claudin-5 forward, 5'-CCTTCATCGGCAACAGCATC-3' and reverse, 5'-CGTACACCTTGCACTGCATC-3'; claudin-7 forward, 5'-ATG GCCAACTCGGGCCTGCAACTG-3' and reverse, 5'-TCACACGTATTCCTTGGAGGAATT-3'; claudin-8 forward, 5'-CGTCTTGGCTTTCTTGGCTTTCAT G-3' and reverse, 5'-GGCAACCCAGCTGACAGG-3'; and GAPDH forward, 5'-AACGTGTCAGTCGTGGACCTG-3' and reverse, 5'-AGTGGGTGTCGCTGTFGAAGT-3'.

Criteria for the positive expression of claudin proteins in gastric tissues. The staining and scoring of the claudin protein expression levels were classified semi-quantitatively based on the total combined scores of the percentage of positively stained tumor cells together with the staining intensity (33). A tumor was scored ' 0 ' if $<5 \%$ of tumor cells stained positive, ' 1 ' if $5-30 \%$ of cells were positive, ' 2 ' if $30-50 \%$ of cells were positive and ' 3 ' if $>50 \%$ of cells were positively stained. The staining intensity was scored as ' 0 ' if no cells were stained or if only weak staining was present, ' 1 ' if moderate staining was present, and ' 2-3' in cases of strong staining. The final score of the claudin protein expression was defined as 'low claudin expression' if the sum of the positivity score and the staining intensity score was $0-1$, and 'high claudin expression' if the sum was 2-3. In each case, $\geq 5$ different areas of the tumor were 
A

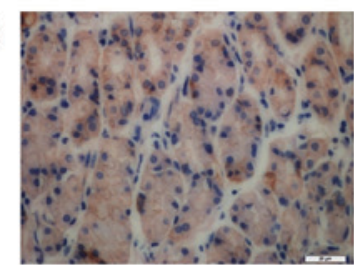

C

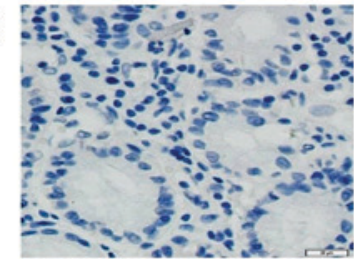

$\mathrm{E}$

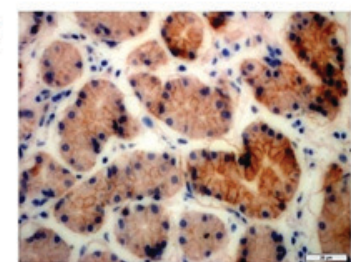

G

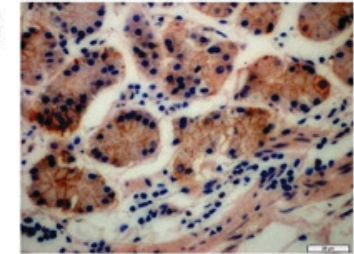

I

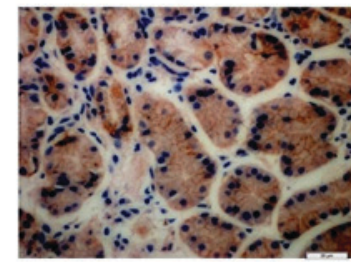

$\mathrm{K}$

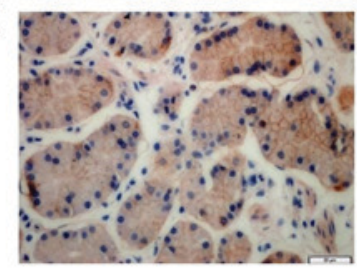

B

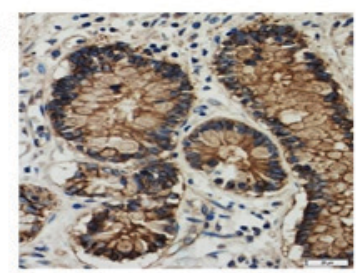

D

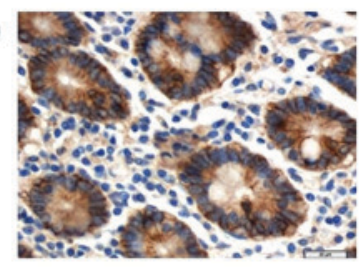

$\mathrm{F}$

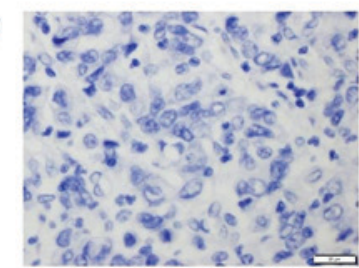

$\mathrm{H}$

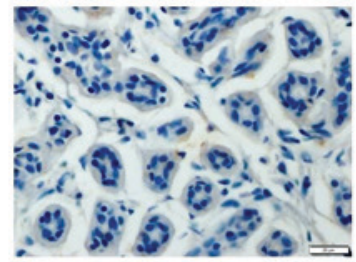

$\mathrm{J}$

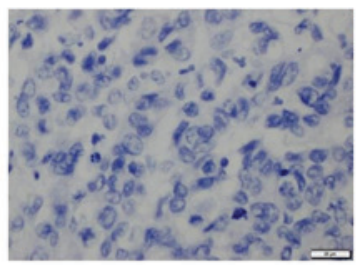

$\mathrm{L}$

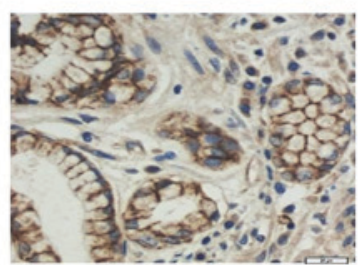

Figure 1. Immunohistochemical demonstration of claudin protein expression in human gastric carcinoma and non-neoplastic tissues. (A and B) Claudin-2 expression in tissues: Non-neoplastic mucosal tissues (left) and in human gastric carcinoma tissue (right). (C and D) Expression of claudin-5 was detected in non-neoplastic mucosal tissues (left) compared with human gastric carcinoma tissues (right). (E and F) Claudin-7 expression in non-neoplastic mucosal tissues (left) compared with human gastric carcinoma tissues (right). ( $\mathrm{G}$ and $\mathrm{H}$ ) Claudin-8 expression was detected in non-neoplastic mucosal tissues (left) and in human gastric carcinoma tissues (right). (I and J) E-cadherin expression was detected in non-neoplastic mucosal tissues (left) and in human gastric carcinoma tissues (right). ( $\mathrm{K}$ and $\mathrm{L}$ ) Expression of a tight junction (zonula occludens-1) was detected in non-neoplastic mucosal tissues (left) and in human gastric carcinoma tissues (right). (magnification, $\mathrm{x} 400$ ).

examined and the mean of the results was used as the final expression score.

Follow-up. Patients were followed-up to 60 months to evaluate metastasis and to determine survival. Survival time was calculated as the time from the beginning of diagnosis to the time of mortality or loss to follow-up. By the end of September 2016,

all patients had received follow-up either on an outpatient basis or by telephone interview. The mortality status of each patient was confirmed.

Statistical analysis. All data are presented as the mean \pm standard deviation. The $\chi^{2}$ test $/ \chi^{2}$ goodness-of-fit test was used to determine the prognostic significance and value. A Student's t-test was used to analyze the significance of the differences between two groups. Origin 7.5 laboratory data analysis software (OriginLab, Northampton, MA, USA) and image processing software (Image-Pro Plus 6.0, Media Cybernetics, Inc., Rockville, MD, USA) were utilized to quantify the data. Survival was analyzed by the Kaplan-Meier method following by log-rank tests.

\section{Results}

Claudin-2 expression in gastric cancer is not notably different compared with that in non-neoplastic mucosa. The expression of claudin proteins was investigated in the membranes of gastric cancer tissues and non-neoplastic mucosal tissues. Claudin-2 was highly expressed in $37.0 \%$ (37/100) of gastric cancer tissues and $41.0 \%$ (41/100) of non-neoplastic tissues. The results of the present study indicated that claudin-2 expression in gastric cancer samples exhibited no notable difference compared with histologically normal gastric tissues $\left(\chi^{2}\right.$ test $/ \chi^{2}$ goodness-of-fit test; $\mathrm{P}=0.374 ;$ Fig. $1 \mathrm{~A}$ and $\left.\mathrm{B}\right)$. The expression of claudin-2 was not associated with age $(\mathrm{P}=1.000)$, histological grade $(\mathrm{P}=1.000)$, Ki67 $(\mathrm{P}=0.232)$, clinical staging $(\mathrm{P}=1.000)$ and lymph node metastasis $(\mathrm{P}=0.368$; Table I). The expression levels of claudin- $-5,-7$ and -8 varied between gastric cancer tissues and in non-neoplastic mucosa.

Membrane expression of claudin-5 was high in $47.0 \%$ (47/100) of gastric cancer tissues and 19.0\% (19/100) of non-neoplastic tissues (Fig. 1C and D). Claudin-7 expression was detected to be high expressed in $22.0 \%(22 / 100)$ of gastric cancer tissues and 54.0\% (54/100) in non-neoplastic tissues (Fig. 1E and F). High expression of claudin-8 protein was detected in $31.0 \%(31 / 100)$ of gastric cancer tissues and $53.0 \%$ (53/100) of non-neoplastic tissues (Fig. 1G and H). A basolateral membrane marker (E-cadherin) and TJ (zonula occludens-1) were used as the positive control, to make the results of claudin localization to the membrane more visible (Fig. 1I-L).

As mentioned previously, the results of the present study suggested that membrane expression of claudin-5 was significantly increased in gastric cancer samples compared with histologically normal gastric tissue $(\mathrm{P}<0.01)$. Additionally, the membrane expression of claudin-7 and claudin-8 in gastric cancer tissues was significantly decreased compared with non-neoplastic tissues $(\mathrm{P}<0.01)$.

As presented in Table I, claudin-5 expression was associated with lymph node metastasis $(\mathrm{P}<0.01)$, although it had no association with age $(\mathrm{P}=0.261)$, histological grade $(\mathrm{P}=0.614)$, clinical staging $(\mathrm{P}=0.863)$ or expression of Ki67 ( $\mathrm{P}=0.443)$. In addition, as presented in Table II, the expression of claudin-7 was associated with clinical staging $(\mathrm{P}<0.01)$ and lymph node metastasis $(\mathrm{P}<0.01)$, although it had no association with age $(\mathrm{P}=0.782)$, expression of Ki67 $(\mathrm{P}=0.382)$ or histological grade $(\mathrm{P}=1.000)$. In addition, the expression of claudin- 8 was 
Table I. Expression of claudin-2 and claudin-5, and the clinicopathological characteristics in patients with gastric carcinoma.

\begin{tabular}{|c|c|c|c|c|c|c|c|c|}
\hline Factor & $\mathrm{n}$ & $\begin{array}{l}\text { Claudin-2 } \\
\text { (high) }\end{array}$ & $\begin{array}{l}\text { Claudin-2 } \\
\text { (low) }\end{array}$ & P-value & $\mathrm{n}$ & $\begin{array}{l}\text { Claudin-5 } \\
\text { (high) }\end{array}$ & $\begin{array}{l}\text { Claudin-5 } \\
\quad \text { (low) }\end{array}$ & P-value \\
\hline Gastric carcinoma tissue & 100 & 37 & 63 & 0.374 & 100 & 47 & 53 & $<0.01$ \\
\hline Non-neoplastic tissue & 100 & 41 & 59 & & 100 & 19 & 81 & \\
\hline \multicolumn{9}{|l|}{ Age, years } \\
\hline$\leq 60$ & 29 & 10 & 19 & $1.000^{\mathrm{a}}$ & 27 & 15 & 12 & $0.261^{\mathrm{a}}$ \\
\hline$>60$ & 71 & 27 & 44 & & 73 & 32 & 41 & \\
\hline \multicolumn{9}{|l|}{ Histological grade } \\
\hline Well-differentiated & 35 & 12 & 23 & $1.000^{\mathrm{a}}$ & 32 & 16 & 16 & $0.614^{\mathrm{a}}$ \\
\hline $\begin{array}{l}\text { Moderately and } \\
\text { poorly-differentiated }\end{array}$ & 65 & 25 & 40 & & 68 & 31 & 37 & \\
\hline \multicolumn{9}{|l|}{ Lymph node metastasis } \\
\hline+ & 46 & 16 & 30 & 0.368 & 39 & 15 & 24 & $<0.01$ \\
\hline- & 64 & 21 & 43 & & 61 & 32 & 29 & \\
\hline \multicolumn{9}{|l|}{ Ki67 } \\
\hline+ & 29 & 11 & 18 & $0.232^{\mathrm{a}}$ & 27 & 12 & 15 & $0.443^{\mathrm{a}}$ \\
\hline- & 71 & 26 & 45 & & 73 & 35 & 38 & \\
\hline \multicolumn{9}{|l|}{ Clinical stage } \\
\hline I-II & 27 & 11 & 16 & $1.000^{\mathrm{a}}$ & 27 & 15 & 12 & $0.863^{\mathrm{a}}$ \\
\hline III-IV & 73 & 26 & 57 & & 73 & 32 & 41 & \\
\hline
\end{tabular}

${ }^{\text {an }}$ o statistical significance was observed with the $\chi^{2}$ test $/ \chi^{2}$ goodness-of-fit test.
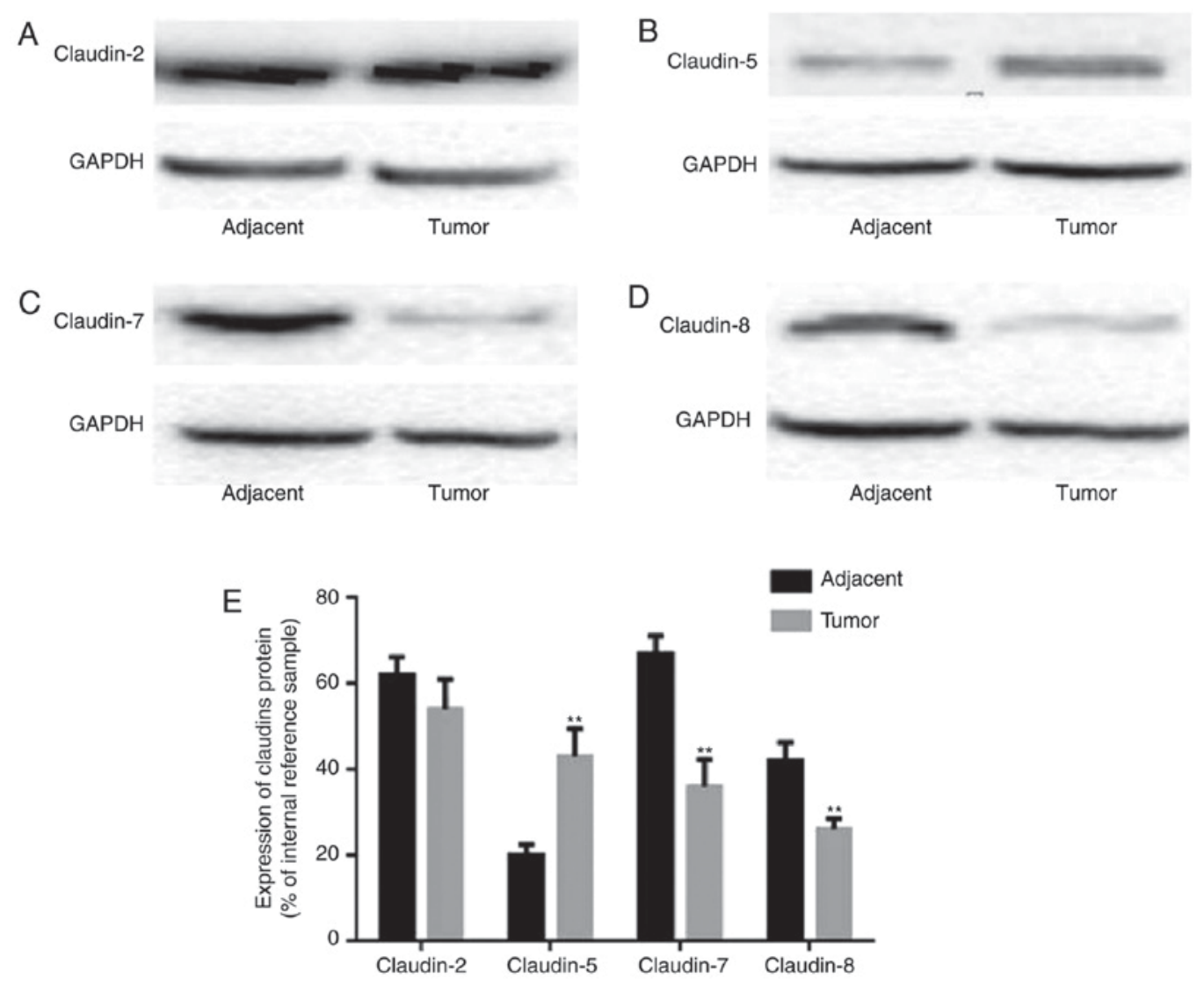

Figure 2. Expression of claudin proteins in human gastric carcinoma and non-neoplastic mucosae. Semi-quantitative immunoblotting was used to investigate statistical differences in the expression of claudin proteins in 12 human gastric carcinoma tissues and non-neoplastic mucosae. The semi-quantitative measurements are expressed as the mean \pm standard deviation and as percentage changes compared with the internal reference sample. (A) Claudin-2 expression, (B) claudin-5 expression, (C) claudin-7 expression and (D) claudin-8 expression. (E) Histograms. ${ }^{* * *}$ P $<0.01$ vs. non-neoplastic tissues. 
Table II. Expression of claudin-7 and claudin- 8 and the clinicopathological characteristics in patients with gastric carcinoma.

\begin{tabular}{|c|c|c|c|c|c|c|c|c|}
\hline Factor & $\mathrm{n}$ & $\begin{array}{l}\text { Claudin-7 } \\
\text { (high) }\end{array}$ & $\begin{array}{l}\text { Claudin-7 } \\
\text { (low) }\end{array}$ & P-value & $\mathrm{n}$ & $\begin{array}{l}\text { Claudin-8 } \\
\text { (high) }\end{array}$ & $\begin{array}{l}\text { Claudin-8 } \\
\text { (low) }\end{array}$ & P-value \\
\hline Gastric carcinoma tissue & 100 & 22 & 78 & $<0.01$ & 100 & 31 & 69 & $<0.01$ \\
\hline Non-neoplastic tissue & 100 & 54 & 46 & & 100 & 53 & 47 & \\
\hline \multicolumn{9}{|l|}{ Age, years } \\
\hline$\leq 60$ & 29 & 6 & 23 & $0.782^{\mathrm{a}}$ & 29 & 8 & 21 & $1.000^{\mathrm{a}}$ \\
\hline$>60$ & 71 & 16 & 55 & & 71 & 23 & 48 & \\
\hline \multicolumn{9}{|l|}{ Histological grade } \\
\hline Well-differentiated & 35 & 7 & 28 & $1.000^{\mathrm{a}}$ & 35 & 8 & 27 & $0.524^{\mathrm{a}}$ \\
\hline $\begin{array}{l}\text { Moderately- and } \\
\text { poorly-differentiated }\end{array}$ & 65 & 15 & 50 & & 65 & 23 & 42 & \\
\hline \multicolumn{9}{|l|}{ Lymph node metastasis } \\
\hline+ & 46 & 6 & 40 & $<0.01$ & 46 & 7 & 39 & $<0.01$ \\
\hline- & 64 & 16 & 48 & & 64 & 24 & 40 & \\
\hline \multicolumn{9}{|l|}{ Ki67 } \\
\hline+ & 29 & 5 & 24 & $0.382^{\mathrm{a}}$ & 29 & 7 & 22 & $0.746^{\mathrm{a}}$ \\
\hline- & 71 & 17 & 54 & & 71 & 24 & 47 & \\
\hline \multicolumn{9}{|l|}{ Clinical stage } \\
\hline I-II & 27 & 12 & 15 & $<0.01$ & 27 & 10 & 17 & $1.000^{\mathrm{a}}$ \\
\hline III-IV & 73 & 10 & 63 & & 73 & 21 & 52 & \\
\hline
\end{tabular}

${ }^{\mathrm{a} N o}$ statistical significance was observed with the $\chi^{2}$ test $/ \chi^{2}$ goodness-of-fit test.

Table III. Association between the expression of claudin-7 and claudin- 8 in gastric carcinoma tissues.

\begin{tabular}{lcccc}
\hline & $\begin{array}{c}\text { Claudin-8 } \\
\text { (high) }\end{array}$ & $\begin{array}{c}\text { Claudin-8 } \\
\text { (low) }\end{array}$ & $\phi^{*}$ & P-value \\
\hline Claudin-7 (high) & 33 & 21 & 0.754 & $<0.01$ \\
Claudin-7 (low) & 20 & 26 & & \\
\hline
\end{tabular}

$\phi^{*}$, Phi coefficient.

associated with lymph node metastasis $(\mathrm{P}<0.01)$, although it had no association with age $(\mathrm{P}=1.000)$, clinical staging $(\mathrm{P}=1.000)$, histological grade $(\mathrm{P}=0.524)$ or expression of Ki67 ( $\mathrm{P}=0.746$; Table II).

Expression of claudin proteins in non-neoplastic mucosa and gastric cancer tissues. Semi-quantitative immunoblotting was utilized to investigate statistical differences in claudin expression between non-neoplastic mucosa and gastric cancer tissues. Claudin-2, $-5,-7$ and -8 were detected at approximately $22 \mathrm{kDa}$ in all tissues. According to the scanning results, claudin-2 expression levels did not exhibit notable differences between gastric cancer tissues and non-neoplastic tissues (Fig. 2A). The expression of claudin-5 was upregulated in gastric cancer tissues compared with in non-neoplastic tissues (Fig. 2B). In addition, the expression of claudin-7 and claudin- 8 was significantly downregulated in gastric cancer tissues compared with non-neoplastic tissues (Fig. 2C and D, respectively).
Table IV. Association between the expression of claudin-7 and claudin-8 in non-neoplastic mucosae.

\begin{tabular}{lcccc}
\hline & $\begin{array}{c}\text { Claudin-8 } \\
\text { (high) }\end{array}$ & $\begin{array}{c}\text { Claudin-8 } \\
\text { (low) }\end{array}$ & $\phi^{*}$ & P-value \\
\hline Claudin-7 (high) & 15 & 7 & 0.782 & $<0.01$ \\
Claudin-7 (low) & 16 & 62 & & \\
\hline
\end{tabular}

$\phi^{*}$, Phi coefficient.

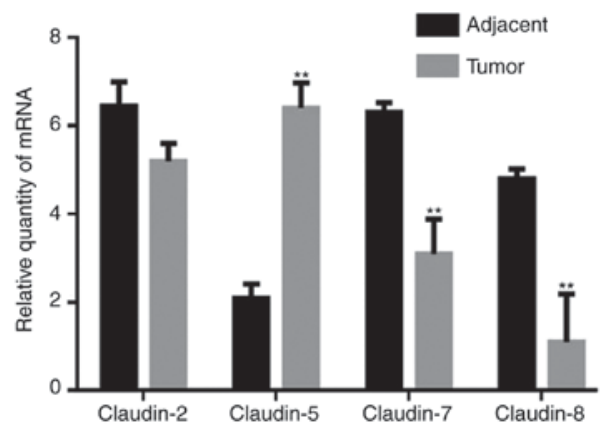

Figure 3. mRNA expression levels of claudins in human gastric carcinoma and non-neoplastic mucosae. Quantitative polymerase chain reaction analysis of claudin expression in 12 human gastric carcinoma tissues and non-neoplastic mucosae. ${ }^{* *} \mathrm{P}<0.01$ vs. non-neoplastic tissues.

The statistical differences in the expression of claudins are presented in Fig. 2E. 

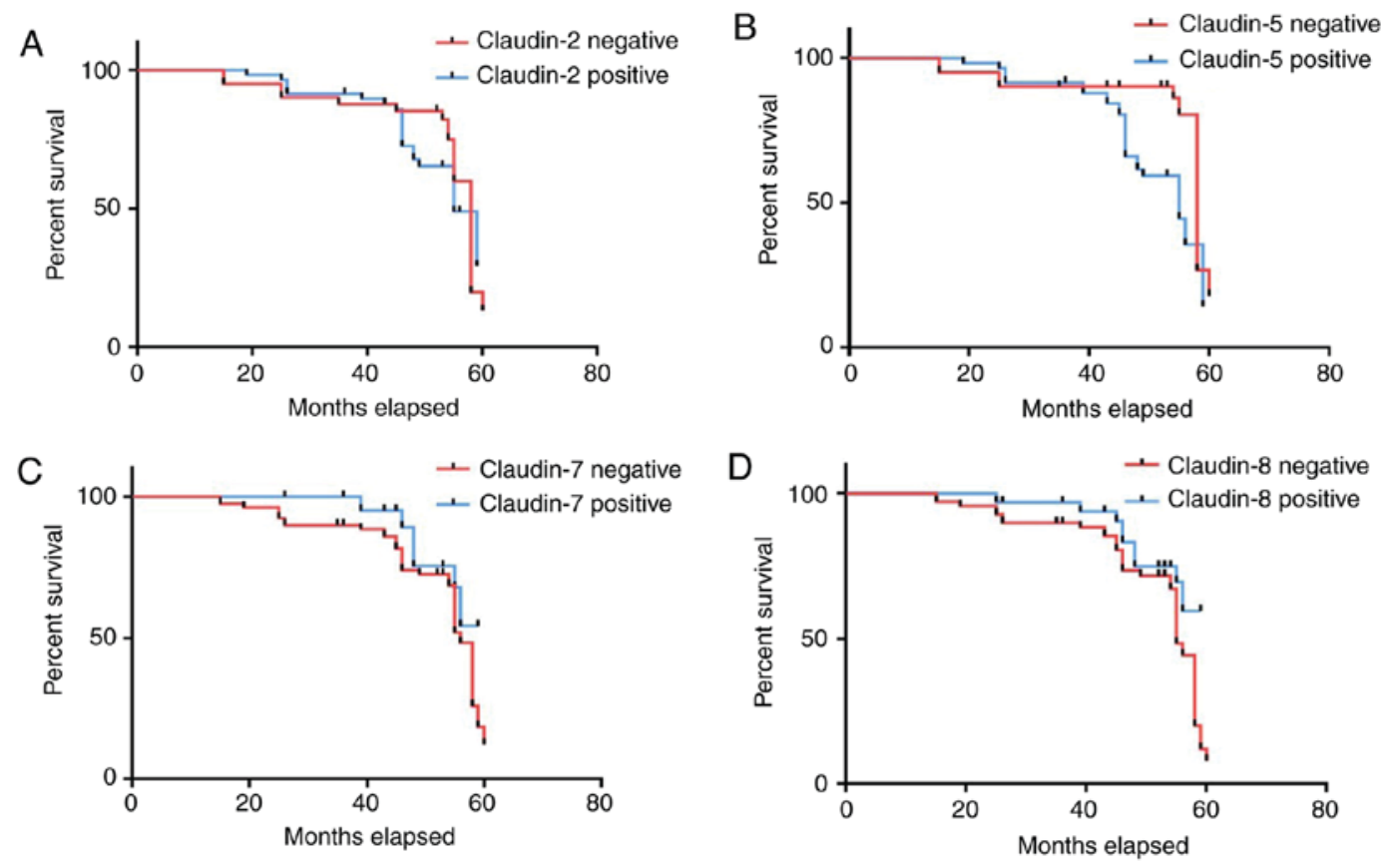

Figure 4. Correlation between the expression of claudins and survival. Kaplan-Meier analysis was used for survival analysis in gastric carcinoma patients. (A) Claudin-2 curve, (B) claudin-5 curve, (C) claudin-7 curve and (D) claudin-8 curve.

Expression of claudin mRNA in gastric cancer and non-neoplastic mucosa. qPCR was used to determine the statistical differences in the mRNA expression of claudins between non-neoplastic mucosa and gastric cancer tissues. As presented in Fig. 3, the difference in claudin-2 mRNA expression levels between gastric cancer tissues and non-neoplastic mucosa was not statistically significant. Compared with non-neoplastic tissues, the mRNA expression levels of claudin-5 were significantly upregulated in gastric cancer tissues, while the mRNA expression levels of claudin-7 and claudin- 8 were significantly downregulated in gastric cancer tissues. This corresponded with the results obtained by immunoblotting.

Claudin-7 and claudin-8 are concurrently expressed in gastric cancer tissues. In addition, the association between claudin-7 and claudin-8 expression in gastric cancers tissues and non-neoplastic mucosa was investigated using the $\chi^{2}$ test $/ \chi^{2}$ goodness-of-fit test. As presented in Tables III and IV, the association between claudin-7 and claudin- 8 was reported.

Clinical correlations and survival. Follow-up ranged between 19 and 60 months. Patients with tumors that were positive for claudin-7 and claudin-8 proteins had a significantly longer survival compared with those whose tumors were negative for these two proteins $(\mathrm{P}=0.002$ and $\mathrm{P}=0.011$, respectively); patients with tumors that were positive for claudin-5 protein expression had a significantly shorter survival duration compared with those whose tumors were negative for this protein ( $\mathrm{P}=0.004$; Fig. 4$)$.

\section{Discussion}

The loss of TJ structure caused by aberrant expression of claudin proteins has been suggested to be of extreme importance in the promotion of the diffusion of nutrients and other factors that are necessary for the survival and proliferation of cancer cells $(34,35)$. Previous research has revealed that the expression of $\mathrm{TJ}$ claudin proteins is frequently altered in various cancers (36). This was demonstrated in a study that suggested that the expression of claudin-1 was downregulated in pancreatic cancer cells and that re-expression of claudin-1 reduced the invasive ability of these cells $(11,36)$. Similarly, it was revealed that the expression of claudin- 8 was downregulated in head and neck cancer, and invasive breast cancer (37). These reports of downregulated claudin protein expression in a variety of human cancer cells are in agreement with the generally accepted idea that tumorigenesis occurs along with the loss of TJ integrity caused by the downregulation of claudin proteins (38-40). Conversely, several studies have suggested that the expression levels of numerous claudin proteins are increased in cancer $(14,41)$. For instance, a number of reports have revealed the upregulation of claudin-3 and claudin-4 in breast cancers (42). Additionally, a majority of the studies published thus far have reported increased expression of claudin proteins in various human cancer types; the differential regulation of claudin proteins in various types of cancer represents an opportunity to determine the mechanism of different therapeutic responses (34,43-45).

In view of the specificity of claudin expression profiles in human cancer, it has been revealed that claudin proteins may serve as useful molecular markers for cancer diagnostics. There are numerous publications on the expression profiles of claudin proteins in gastric cancer. For instance, it has been demonstrated that claudin-1 may be a biomarker for intestinal-type gastric cancer with reduced survival (46). Claudin-4 was significantly correlated with tumor $\mathrm{T}$ stage and with intestinal type classification in gastric cancer (47). In addition, the expression of claudin-10 and claudin- 17 was downregulated, while the expression of claudin-14 was 
upregulated, in gastric cancer tissues compared with in tumor adjacent tissues (48). The expression of claudin-11 and -23 was greatly increased in paracancerous gastric tissue compared with cancerous tissue (49). These results suggested that the functions of claudin proteins may be highly tissue-specific and may be the candidate biomarkers of gastric cancer progression. Additionally, Lin et al (34) revealed that the expression of the TJ proteins claudin-2, -6 and -11 varies between human gastric cancer and adjacent non-neoplastic tissues. The expression of claudin- 2 and claudin- 6 was downregulated while the expression of claudin-11 was upregulated in gastric cancer tissue. Differing from the results of the present study, the localizations of claudin proteins in research of Lin et al (34) were distributed in the cytoplasm and the expression of claudin-2 was downregulated in gastric cancer tissues compared with adjacent non-neoplastic tissues. There were certain notable deficiencies in research of Lin et al (34); for example, the localizations of claudin proteins were distributed in cytoplasm, and they did not appear to be TJ-associated; only 28 samples of non-neoplastic tissues adjacent to the tumors, rather than non-neoplastic mucosal tissues, were examined for the expression of claudin proteins. In summary, testing the application of claudins as cancer biomarkers in gastric cancer is not novel; however, the expression profiles of the TJ proteins claudin-2, $-5,-7$ and -8 in gastric cancer and gastric non-neoplastic mucosal tissues requires further investigation.

In the present study, it was revealed that the expression levels of claudin-7 and claudin- 8 were downregulated, while the expression levels of claudin-5 were upregulated in gastric carcinoma compared with non-neoplastic mucosa. The correlations between the expression of claudin-5, -7 and -8 and lymph node metastasis were additionally observed, which revealed that the expression levels of these claudins may have the potential to be established as prognostic indicators in patients with gastric carcinoma. In addition, claudin-7 and claudin- 8 were concurrently expressed in the mucosae and in gastric carcinoma tissues, which suggested that claudin-7 and claudin-8 may participate in the composition of TJ structure in gastric tissues. In addition, patients with tumors that were positive for claudin-7 and claudin-8 protein expression had a significantly longer survival time compared with those with negative tumors, while those with tumors that were positive for claudin-5 protein expression had a significantly shorter survival time compared with those with negative tumors.

In view of the observations made in the present study, patients may be screened following surgery for the expression of these claudin proteins. Due to the association between the expression of these claudin proteins and survival, these proteins may represent novel tumor markers and therapeutic targets. In the future, the specific mechanism that is responsible for the observations in the present study, on how alterations in claudin protein expression affect the malignant and oncogenic phenotype of gastric carcinoma, may be investigated.

In summary, the results of the present study inferred that the expression of claudin-5, -7 and -8 was altered between human non-neoplastic mucosa and gastric carcinoma tissues, and that their expression was associated with lymph node metastasis. Additionally, claudin-7 and claudin- 8 were concurrently expressed in non-neoplastic mucosal and gastric carcinoma tissues.

\section{Acknowledgements}

The authors would like to thank Dr William Orr, Department of Pathology, University of Manitoba, Canada, for help with this manuscript.

\section{Funding}

No funding was received.

\section{Availability of data and materials}

The datasets used and/or analyzed during the present study are available from the corresponding author on reasonable request.

\section{Authors' contributions}

LY performed the experiments and analyzed the data. XS contributed to the conception and design of the study. XM designed the present study and revised the manuscript. All authors read and approved the final manuscript.

\section{Ethics approval and consent to participate}

All procedures performed in the present study involving human participants were in accordance with the ethical standards of the institutional and/or national research committee and with the 1964 Helsinki declaration and its later amendments or comparable ethical standards. The present study (no. JLU01354) was approved by the Ethics Committee of Jilin University. This article does not contain any studies with animals performed by any of the authors.

\section{Consent for publication}

Not applicable.

\section{Competing interest}

The authors declare that they have no competing interests.

\section{References}

1. Dejana E: Endothelial cell-cell junctions: Happy together. Nat Rev Mol Cell Biol 5: 261-270, 2004.

2. Brandner JM, Haftek M and Niessen CM: Adherens junctions, desmosomes and tight junctions in epidermal barrier function. Open Dermatol J 4: 14-20, 2010.

3. Förster C: Tight junctions and the modulation of barrier function in disease. Histochem Cell Biol 130: 55-70, 2008.

4. Niessen CM: Tight junctions/adherens junctions: Basic structure and function. J Invest Dermatol 127: 2525-2532, 2007.

5. Martin TA and Jiang WG: Loss of tight junction barrier function and its role in cancer metastasis. Biochim Biophys Acta 1788: 872-891, 2009.

6. Schneeberger EE and Lynch RD: The tight junction: A multifunctional complex. Am J Physiol Cell Physiol 286: C1213-C1228, 2004.

7. Zhang GH, Wu L and Yu GY: Tight junctions and paracellular fluid and ion transport in salivary glands. Chin J Dent Res 16: 13-46, 2013.

8. Van Itallie CM and Anderson JM: The molecular physiology of tight junction pores. Physiology (Bethesda) 19: 331-338, 2004.

9. Coradini D, Casarsa C and Oriana S: Epithelial cell polarity and tumorigenesis: New perspectives for cancer detection and treatment. Acta Pharmacol Sin 32: 552-564, 2011. 
10. Lee M and Vasioukhin V: Cell polarity and cancer-cell and tissue polarity as a non-canonical tumor suppressor. J Cell Sci 121: 1141-1150, 2008.

11. Morin PJ: Claudin proteins in human cancer: Promising new targets for diagnosis and therapy. Cancer Res 65: 9603-9606, 2005.

12. Tabariès $\mathrm{S}$ and Siegel PM: The role of claudins in cancer metastasis. Oncogene 36: 1176-1190, 2017.

13. González-Mariscal L, Tapia R and Chamorro D: Crosstalk of tight junction components with signaling pathways. Biochim Biophys Acta 1778: 729-756, 2008.

14. Oliveira S and Morgado-Díaz JA: Claudins: Multifunctional players in epithelial tight junctions and their role in cancer. Cell Mol Life Sci 64: 17-28, 2007.

15. Morita K, Furuse M, Fujimoto K and Tsukita S: Claudin multigene family encoding four-transmembrane domain protein components of tight junction strands. Proc Natl Acad Sci 96: 511-516, 1999.

16. Krause G, Winkler L, Mueller SL, Haseloff RF, Piontek J and Blasig IE: Structure and function of claudins. Biochim Biophy Acta 1778: 631-645, 2008.

17. Elkouby-Naor L and Ben-Yosef T: Functions of claudin tight junction proteins and their complex interactions in various physiological systems. Int Rev Cell Mol Biol 279: 1-32, 2010.

18. Findley MK and Koval M: Regulation and roles for claudin-family tight junction proteins. IUBMB Life 61: 431-437, 2009.

19. Lal-Nag M and Morin PJ: The claudins. Genome Biol 10: 235, 2009.

20. Ikari A, Sato T, Watanabe R, Yamazaki Y and Sugatani J: Increase in claudin-2 expression by an EGFR/MEK/ERK/c-Fos pathway in lung adenocarcinoma A549 cells. Biochim Biophy Acta 1823: 1110-1118, 2012.

21. Itoh M, Furuse M, Morita K, Kubota K, Saitou M and Tsukita S: Direct binding of three tight junction-associated MAGUKs, $\mathrm{ZO}-1, \mathrm{ZO}-2$, and $\mathrm{ZO}-3$, with the $\mathrm{COOH}$ termini of claudins. J Cell Biol 147: 1351-1363, 1999.

22. D'Souza T, Agarwal R and Morin PJ: Phosphorylation of claudin-3 at threonine 192 by cAMP-dependent protein kinase regulates tight junction barrier function in ovarian cancer cells. J Biol Chem 280: 26233-26240, 2005.

23. D'Souza T, Indig FE and Morin PJ: Phosphorylation of claudin-4 by PKCepsilon regulates tight junction barrier function in ovarian cancer cells. Exp Cell Res 313: 3364-3375, 2007.

24. Kominsky SL: Claudins: Emerging targets for cancer therapy. Expert Rev Mol Med 8: 1-11, 2006.

25. Furuse $\mathrm{M}$ and Tsukita S: Claudins in occluding junctions of humans and flies. Trends Cell Biol 16: 181-188, 2006.

26. Günzel D and Alan S: Claudins and the modulation of tight junction permeability. Physiol Rev 93: 525-569, 2013.

27. Ouban A and Ahmed AA: Claudins in human cancer: A review. Histol Histopathol 25: 83-90, 2010.

28. Osanai M, Takasawa A, Murata M and Sawada N: Claudins in cancer: Bench to bedside. Pflugers Arch 469: 55-67, 2017.

29. Kwon MJ: Emerging roles of claudins in human cancer. Int J Mol Sci 14: 18148-18180, 2013.

30. Katai H, Yoshimura K, Maruyama K, Sasako M and Sano T: Evaluation of the New International Union Against Cancer TNM staging for gastric carcinoma. Cancer 88: 1796-1800, 2000.

31. Pan XY, Wang B, Che YC, Weng ZP, Dai HY and Peng W: Expression of claudin-3 and claudin-4 in normal, hyperplastic, and malignant endometrial tissue. Int J Gynecol Cancer 17: 233-241, 2007.

32. Livak KJ and Schmittgen TD: Analysis of relative gene expression data using real-time quantitative PCR and the 2(-delta delta C(T)) method. Methods 25: 402-408, 2001.
33. Yang Y, Yang H, McNutt MA, Xiong F, Nie X, Li L and Zhou R: LAPTM4B overexpression is an independent prognostic marker in ovarian carcinoma. Oncol Rep 20: 1077-1083, 2008.

34. Lin Z, Zhang X, Liu Z, Liu Q, Wang L, Lu Y, Liu Y, Wang M, Yang M, Jin X and Quan C: The distinct expression patterns of claudin-2, -6 , and -11 between human gastric neoplasms and adjacent non-neoplastic tissues. Diagn Pathol 8: 133, 2013.

35. Lu Z: Functions of claudin-7 in human lung cancer. 2012.

36. Hewitt KJ, Agarwal R and Morin PJ: The claudin gene family: Expression in normal and neoplastic tissues. BMC Cancer 6: 186, 2006.

37. Kominsky SL, Argani P, Korz D, Evron E, Raman V, Garrett E, Rein A, Sauter G, Kallioniemi OP and Sukumar S: Loss of the tight junction protein claudin-7 correlates with histological grade in both ductal carcinoma in situ and invasive ductal carcinoma of the breast. Oncogene 22: 2021-2033, 2003.

38. Singh AB, Sharma A and Dhawan P: Claudin family of proteins and cancer: An overview. J Oncol 2010: 541957, 2010.

39. Swisshelm K, Macek R and Kubbies M: Role of claudins in tumorigenesis. Adv Drug Deliv Rev 57: 919-928, 2005.

40. Webb PG, Spillman MA and Baumgartner HK: Claudins play a role in normal and tumor cell motility. BMC Cell Biol 14: 19, 2013.

41. Rangel LB, Agarwal R, D'Souza T, Pizer ES, Alò PL, Lancaster WD, Gregoire L, Schwartz DR, Cho KR and Morin PJ: Tight junction proteins claudin-3 and claudin- 4 are frequently overexpressed in ovarian cancer but not in ovarian cystadenomas. Clin Cancer Res 9: 2567-2575, 2003.

42. Szász MA: Claudins as prognostic factors of breast cancer. Magy Onkol 56: 209-212, 2012 (In Hungarian).

43. Zhang X, Ruan Y, Li Y, Lin D, Liu Z and Quan C: Expression of apoptosis signal-regulating kinase 1 is associated with tight junction protein claudin-6 in cervical carcinoma. Int J Clin Exp Pathol 8: 5535-5541, 2015.

44. Wang $\mathrm{H}$ and Yang $\mathrm{X}$ : The expression patterns of tight junction protein claudin-1, -3 , and -4 in human gastric neoplasms and adjacent non-neoplastic tissues. Int J Clin Exp Pathol 8: 881-887, 2015.

45. Zhu J, Wang R, Cao H, Zhang H, Xu S, Wang A, Liu B, Wang Y and Wang R: Expression of claudin-5, $-7,-8$ and -9 in cervical carcinoma tissues and adjacent non-neoplastic tissues. Int J Clin Exp Pathol 8: 9479-9486, 2015.

46. Huang J, Li J, Qu Y, Zhang J, Zhang L, Chen X, Liu B and Zhu Z: The expression of claudin 1 correlates with $\beta$-catenin and is a prognostic factor of poor outcome in gastric cancer. Int J Oncol 44: 1293-1301, 2014.

47. Zhu JL, Gao P, Wang ZN, Song YX, Li AL, Xu YY, Wang MX and Xu HM: Clinicopathological significance of claudin-4 in gastric carcinoma. World J Surg Oncol 11: 150, 2013.

48. Gao M, Li W, Wang $\mathrm{H}$ and Wang G: The distinct expression patterns of claudin-10, -14, -17 and E-cadherin between adjacent non-neoplastic tissues and gastric cancer tissues. Diagn Pathol 8: $205,2013$.

49. Lu Y, Jing J, Sun L, Gong Y, Chen M, Wang Z, Sun M and Yuan Y: Expression of claudin-11, -23 in different gastric tissues and its relationship with the risk and prognosis of gastric cancer. PLoS One 12: e0174476, 2017.

This work is licensed under a Creative Commons Attribution-NonCommercial-NoDerivatives 4.0 International (CC BY-NC-ND 4.0) License. 